\title{
A high resolution polarimetric L-band SAR-design and first results
}

Skou, Niels; Granholm, Johan; Woelders, Kim; Rohde, J; Dall, Jørgen; Christensen, Erik Lintz

Published in:

Proceedings of the International Geoscience and Remote Sensing Symposium

Link to article, DOI:

10.1109/IGARSS.1995.524024

Publication date:

1995

Document Version

Publisher's PDF, also known as Version of record

Link back to DTU Orbit

Citation (APA):

Skou, N., Granholm, J., Woelders, K., Rohde, J., Dall, J., \& Christensen, E. L. (1995). A high resolution polarimetric L-band SAR-design and first results. In Proceedings of the International Geoscience and Remote Sensing Symposium: Quantitative Remote Sensing for Science and Applications (Vol. Volume 3, pp. 17791782). IEEE. https://doi.org/10.1109/IGARSS.1995.524024

\section{General rights}

Copyright and moral rights for the publications made accessible in the public portal are retained by the authors and/or other copyright owners and it is a condition of accessing publications that users recognise and abide by the legal requirements associated with these rights.

- Users may download and print one copy of any publication from the public portal for the purpose of private study or research.

- You may not further distribute the material or use it for any profit-making activity or commercial gain

- You may freely distribute the URL identifying the publication in the public portal 


\title{
A high Resolution Polarimetric L-Band SAR - Design and First Results
}

\author{
N. Skou, J. Granholm, K. Woelders, J. Rohde, J. Dall, and E. L. Christensen \\ Danish Center for Remote Sensing, Electromagnetics Institute \\ Technical University of Denmark (TUD), B-348, DK 2800 Lyngby, Denmark. \\ Phone: (45) 458814 44, Fax: (45) 4593 16 34, E-mail: ns@emi.dtu.dk
}

\begin{abstract}
An L-band polarimetric SAR system has been developed as part of the dual frequency (L- \& C-band), polarimetric, airborne EMISAR* system. The SAR features a unique combination of fine resolution $(2 \times 2 \mathrm{~m})$ and wide swath $(9.3$ $\mathrm{km}$ ). The transmitter power is $6 \mathrm{~kW}$. From a flight altitude of $41,000 \mathrm{ft}$ the range of the radar is $64 \mathrm{~km}$ with a noise equivalent sigma naught of $-20 \mathrm{~dB}$. The antenna is a stacked microstrip patch array with the feed structure on the back side of the antenna panel to reduce unwanted radiation. The cross polar level is below $-35 \mathrm{~dB}$. The polarization switch is a relatively conventional PIN diode switch matrix able to sustain the $6 \mathrm{~kW}$ peak power from the transmitter still exhibiting low loss $(0.3 \mathrm{~dB})$ and high isolation (more than $50 \mathrm{~dB}$ ). Thus system cross talk (between polarizations) is dominated by antenna cross talk and is some $-35 \mathrm{~dB}$. Polarimetric imagery has been acquired over the EMISAR calibration scene: An agricultural site in Denmark featuring a range of different fields and forested areas as well as several trihedrals and dihedrals. Based on the imagery data, sensor performance is assessed. The $\mathrm{L} \& \mathrm{C}$-band polarimetric EMISAR instrument is one of the key sensors in the JRC EARSEC initiative aiming at supplying state-of-the-art remote sensing data to European scientists.
\end{abstract}

\section{Introduction}

Since 1989 Electromagnetics Institute (EMI) has flown a Cband, vertically polarized, Synthetic Aperture Radar (SAR) with a 2 by $2 \mathrm{~m}$ resolution and an $80 \mathrm{~km}$ range, [1]. A full swath, full resolution real-time processor was completed in 1992, [2] and [3]. A fully polarimetric version of the C-band system was implemented, and first flown in the fall of 1993, [4]. Finally the L-band system with full polarimetric capability was completed and tested early 1995 .

The EMISAR system is presently operated on a Gulfstream G-3 aircraft of the Royal Danish Air Force. The $\mathrm{G}-3$ is a twin engine jet, with a $6000 \mathrm{~km}$ range. The SAR is nominally operated at an altitude of $41,000 \mathrm{ft}$. The antenna system and the radar INU are installed in a pod mounted be-

\footnotetext{
* Development of the EMISAR system has been sponsored by the Thomas B. Thriges Foundation, the Danish Technical Research Council (STVF), the Royal Danish Air Force (RDAF), the Technical University of Denmark, and the Joint Research Centre (JRC). Data acquisitions have been sponsored by the RDAF, STVF, JRC, and the European Space Agency, ESA.
}

low the fuselage, which facilitates rapid system installation and dismount. Typically the installation time is 2 hours.

One of the applications of the system is EMI's own radar research which is to be carried out as part of the research plan for the "Danish Center for Remote Sensing" which was established early 1994 at EMI by the Danish National Research Foundation. Furthermore, the upgrading to polarimetry and dual frequency capability has been supported by Joint Research Centre (JRC) of the European Community and it is planned that EMI will operate the polarimetric SAR for JRC in connection with EARSEC (European Airborne Remote Sensing Capabilities), a remote sensing program managed and sponsored by JRC. Also, the sensor is used in connection with EMAC (European Multisensor Airborne Campaigns) organised by ESA.

\section{SAR System Overview}

A block diagram of the polarimetric SAR is shown in Fig. 1. Each of the shaded rectangles represents one physical unit. The Pod holding the 3-axis stabilized, dual polarized antenna (shown as two antennas to illustrate the principle) is mounted under the fuselage of the aircraft. The receiver and upconverter (RX-UPC), the transmitter (TX), the High Speed Digital Processor (HSDP), and the System Control Unit (SCU) are 19" boxes located in the aircraft cabin.

The function of the system can be explained as follows: A frequency modulated baseband pulse is computed and stored in the DSG (Digital Signal Generator) buffer. At 200 $\mathrm{MHz}$ rate this pulse is D/A converted, I-Q modulated onto a $300 \mathrm{MHz} I F$, up-converted to the SAR frequency, amplified, and finally transmitted by the antenna. Echoes are received, amplified, down-converted, demodulated and digitised. An optional range pre-filtering (RPF) can then be performed whereafter the peak data rate is reduced by the buffer in the Digital Front End (DFE), thus facilitating the optional azimuth pre-filtering (APF). The pre-filtered data are recorded on a High Density Digital Tape (HDDT) as well as processed by the real-time processor (one channel only) for display on a monitor simultaneously with the data acquisition.

The H/V switch ensures that the pulses are alternately transmitted with horizontal and vertical polarization. Thus one single transmitter is used, while a dual receiver system is needed to record both like and cross polar signals.

A feature of EMISAR is the internal calibration loops $[5],[6]$. Just before and after mapping a scene, pulses having the same coding as the transmitted pulses, can be routed through all units of the radar excluding only the antenna. Thus the complex transfer function of practically the com- 


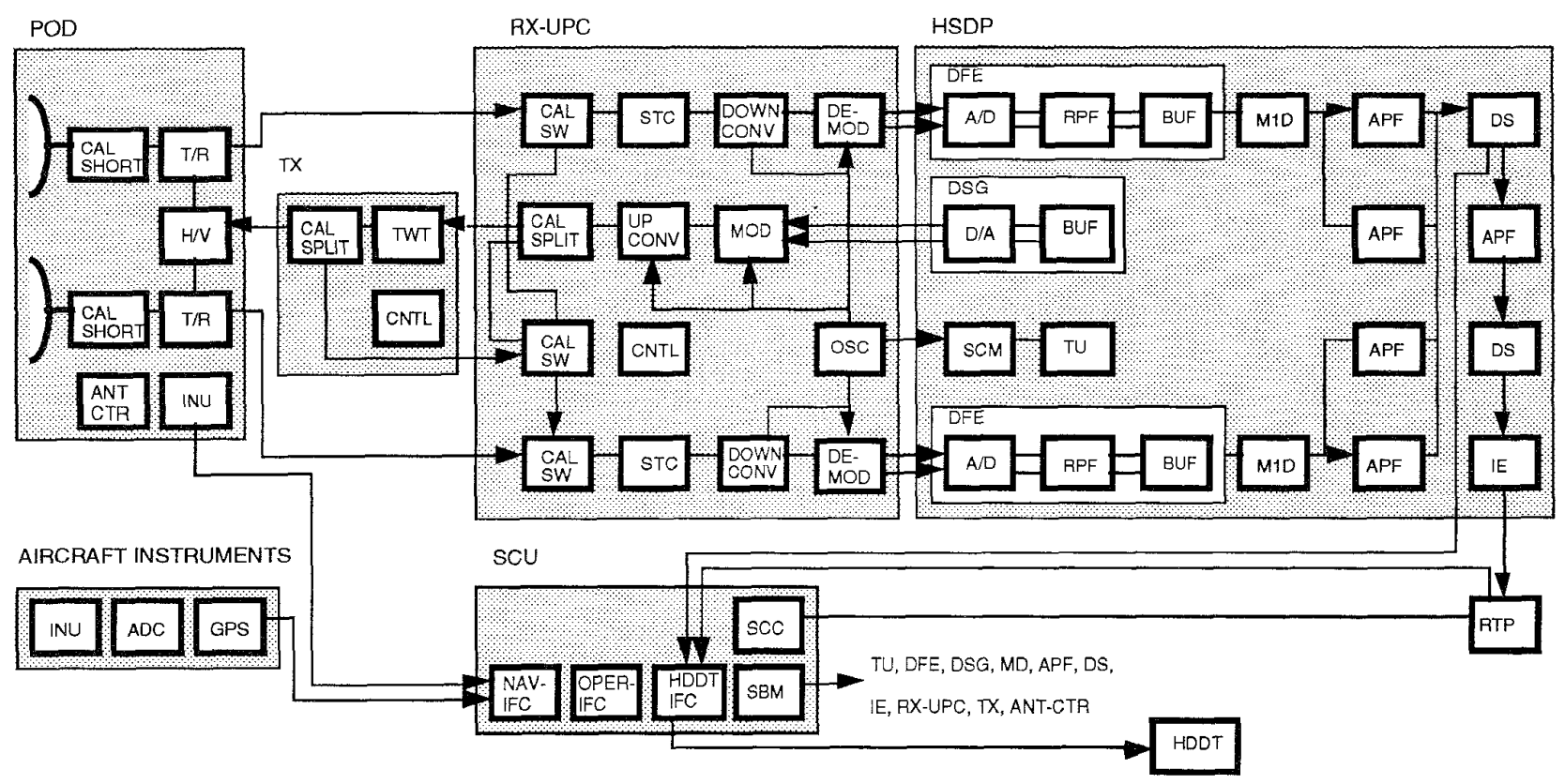

Fig. 1, EMISAR C- and L-band polarimetric SAR overview diagram.

plete radar is measured and the results used to correct the echo data recorded between calibrations. Stability between calibrations is enhanced by temperature control of the ana$\log$ sections of the radar.

The System Control Unit (SCU) is the unit which controls the entire radar system. Its purpose is to provide an interface to the SAR system operator, communicate with all units of the SAR system including setting them up as desired for the mission and checking their status, communicate

Table 1, EMISAR L-band system parameters

\begin{tabular}{|l|l|}
\hline System Parameters & \\
\hline Frequency & L-Band, $1.25 \mathrm{GHz}$ \\
\hline Transmitted power & $6 \mathrm{~kW}$ \\
\hline Receiver noise figure & $1.5 \mathrm{~dB}$ \\
\hline System loss & $4 \mathrm{~dB}$ \\
\hline Pulse length & $0.64-20 \mu \mathrm{s}$ \\
\hline Bandwidth & $100 \mathrm{MHz}$ \\
\hline Antenna gain & $18 \mathrm{dBi}$ \\
\hline Azimuth 3 dB beamwidth & $10^{\circ}$ \\
\hline Elevation 3 dB beamwidth & $42^{\circ}$ \\
\hline Polarization & Fully polarimetric \\
\hline Antenna cross polarization & $<-35 \mathrm{~dB}$ \\
\hline Azimuth ambiguity & $<-30 \mathrm{~dB}$ \\
\hline Resolution in range & 2,4 or $8 \mathrm{~m}$ \\
\hline Resolution in azimuth & 2,4 or $8 \mathrm{~m}$ \\
\hline Swath width & 12,24 or $48 \mathrm{~km}$ \\
\hline Flight altitude & Typically $41,000 \mathrm{ft}$ \\
\hline Real-time processing (1 channel) & Full resolution \\
\hline Range & Max. 64 km \\
\hline PSLR & $-30 \mathrm{~dB}(\mathrm{TBC})$ \\
\hline ISLR & $-25 \mathrm{~dB}(\mathrm{TBC})$ \\
\hline Intrinsic cross-talk terms & $<-35 \mathrm{~dB}$ \\
\hline Calibrated cross-talk terms & TBD \\
\hline
\end{tabular}

with aircraft navigation instruments, and implement a wide range of system verification tests to facilitate troubleshooting. Table 1 lists the basic parameters of the L-band SAR.

\section{Antenna Design}

The L-band antenna design is basically the same as for the C-band system antenna [7], [8]. The antenna size is $1.35 \mathrm{x}$ $0.31 \times 0.11 \mathrm{~m}(\mathrm{LxHxD})$, and consists of 4 identical panels. Each panel contains 4 probe-fed stacked microstrip patches.

The patch configuration is shown in Fig. 2. The upper and lower patches are squares with side lengths $\sim 85$ and $100 \mathrm{~mm}$ respectively. The lower patch is fed using probes, offset $\mathrm{D}=27 \mathrm{~mm}$ from the edge. The patches are etched on $0.381 \mathrm{~mm}$ Rogers RT/duroid 5870 substrate. The dielectric between the upper and lower patch, and between the lower patch and the ground plane is Rohacell $31 \mathrm{HF}$ low permittivity $\left(\varepsilon_{\mathrm{r}}=1.08 @ 1.25 \mathrm{GHz}\right)$ substrate, 16 and $8 \mathrm{~mm}$ respectively. The lower substrate is glued onto a $3 \mathrm{~mm}$ silverplated aluminum ground plane. On the other side of the aluminum ground plane the patch feed network, made on $1.52 \mathrm{~mm}$ Rogers RO3003, is located.

The patch feed network, which feeds the 4 patches in a

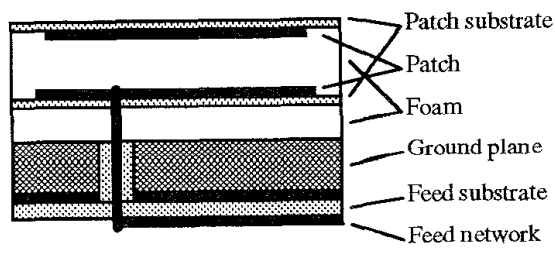

Fig. 2, Patch configuration. 
panel, is designed to excite the patches with equal amplitude and phase, and to give a $50 \Omega$ input impedance for both the $\mathrm{H}$ - and V-port of a panel. The panel feed network feeds the four panels with a 0.61 .01 .00 .6 amplitude taper in order to improve the SAR-system azimuth ambiguity performance.

The measured radiation patterns (directivity) in the azimuth and elevation planes for the vertical polarization are shown in Fig. 3 and 4. The notation used is that $E_{\mathrm{yh}}$ is the $\mathrm{H}$-polarized field component from the antenna fed at the $\mathrm{V}$ port (the H-port patterns are quite similar). The outstanding cross-polarization suppression should be noted.

Fig. 5 shows the measured input reflection coefficients for the $\mathrm{H}$ - and $\mathrm{V}$ - ports, and the transmission between the ports. The exceptionally good isolation between the $H-$ and $\mathrm{V}$ - ports is one of the main reasons for the good cross-pol performance of the antenna.

\section{Polarization Switch}

The polarization switch has been realized in microstrip technology. It is a conventional SPDT switch which utilizes high power microwave PIN diodes as switching elements. The basic structure of the switch is shown in Fig. 6. Each branch in the SPDT switch contains three shunt diodes and DC-blocks in both ends. These DC-blocks consist of two high power capacitors each. N-type stripline launchers have been used as both input and output connectors.

A low loss path is established between the input and one of the outputs by applying reverse bias to the diodes in that

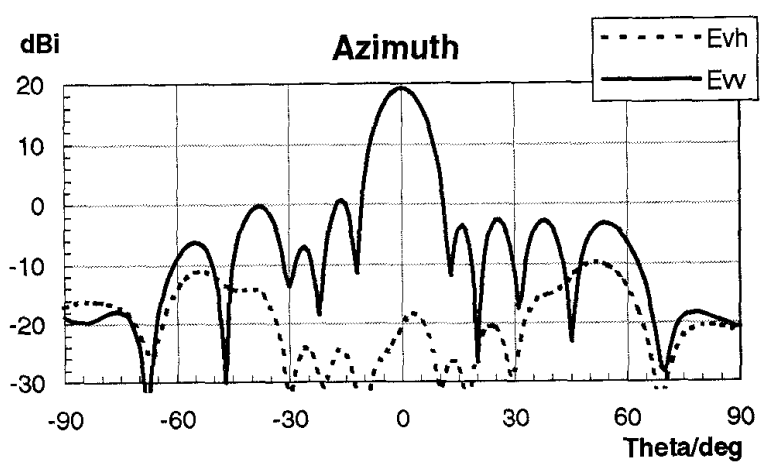

Fig. 3, Radiation pattern in azimuth (V-port, $1.25 \mathrm{GHz}$ ).

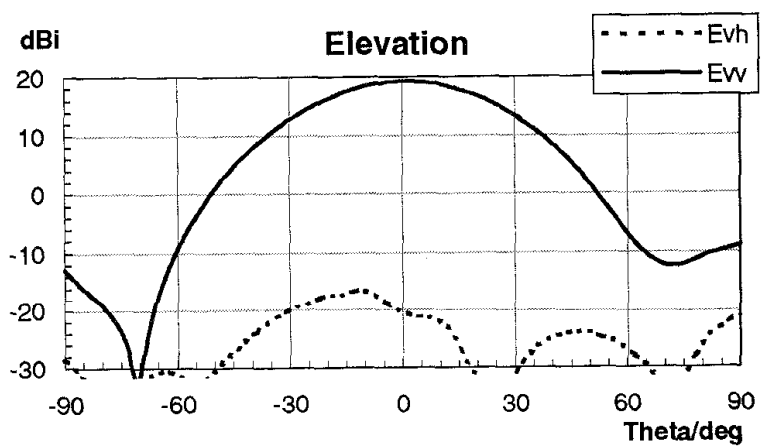

Fig. 4, Radiation pattern in elevation (V-port, $1.25 \mathrm{GHz}$ ).

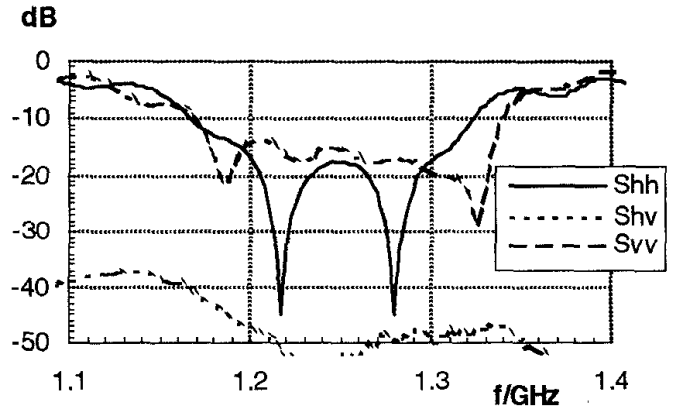

Fig. 5, Input reflection coefficients ( $S_{\mathrm{HH}}$ and $\left.S_{\mathrm{VV}}\right)$ and transmission $\left(\mathrm{S}_{\mathrm{HV}}\right)$.

branch. High isolation is obtained by applying forward bias to the branch instead. In order to achieve the SPDT switch effect, reverse bias is applied to one branch and forward bias is applied to the other branch. The SPDT unit includes an external bias circuit. Bias is supplied via feed-thru capacitors and air coils to each branch of the switch. The external bias circuit and the bias feed arrangement is not shown in Fig. 6 but the bias feeding points have been indicated. The external bias circuit is controlled by a TTL compatible signal and the switching time is appr. $10 \mu$ s.

Receiver protection has also been implemented with PIN diodes. An SPST switch arrangement has been used for this purpose. It is basically a one-branch version of the SPDT switch. This SPST switch unit includes a built-in bias circuit controlled by a TTL compatible signal and it is capable of switching from low-loss mode to high-isolation mode in appr. $1.5 \mu$ s. Switching the opposite way is done in appr. 10 $\mu \mathrm{s}$.

It has been verified that the SPDT switch is capable of handling the $6 \mathrm{~kW}$ from the transmitter. The switch exhibits an insertion loss of $0.3 \mathrm{~dB}$ and an isolation of more than 50 $\mathrm{dB}$. The receiver protection unit exhibits a similar insertion loss and an isolation of appr. $40 \mathrm{~dB}$.

\section{Performance Assessment}

The first test flight was conducted on March 2. The system itself functioned as it was expected to, but a variety of interfering radars and navigation systems appeared to operate within EMISAR's bandwidth. The interference problem was also observed during the EMAC campaign to Northern Scandinavia, March 22-23. Some images are badly contam-

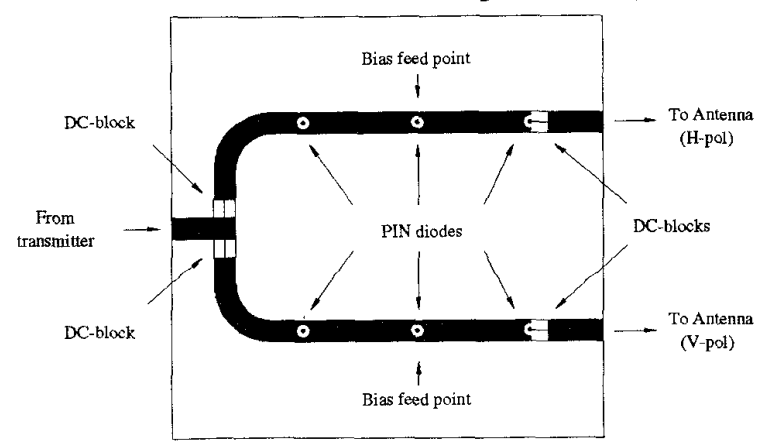

Fig. 6, L-band polarization switch. 
inated, while others barely reveal the interference. Unless it is eliminated by a dedicated filter, the interference rather than the thermal noise and the quantisation noise governs the signal-to-noise ratio. At the time of writing, a first attempt has been made to eliminate the interfering signals, but still they have an impact on the performance assessment summarized in the following.

Due to the wide elevation pattern of the microstrip antenna, the issues of right-left ambiguity and multipath propagation caused by wing reflections had been devoted special attention during the design of the L-band system [9]. So far the imagery has only been visually inspected, but none of the phenomenons have been found.

The performance assessment is based on two scenes acquired on March 2 and March 22, respectively. They both cover the Danish calibration test site at Foulum where three $2 \mathrm{~m}$ trihedrals and four $0.9 \mathrm{~m}$ dihedrals were deployed at three different ranges.

The $3 \mathrm{~dB}$ resolution has been found to be $2.11 \mathrm{~m}$ in azimuth and $2.07 \mathrm{~m}$ in range. Relying almost exclusively on the pre-map and post-map internal calibrations, the system must be very stable during the period of data acquisition in order to meet the calibration requirements. This is indeed the case, as the maximum absolute amplitude drift of the calibration signals has been found to be $0.1 \mathrm{~dB}$. For the channal balance, an amplitude drift of $0.04 \mathrm{~dB}$ and a phase drift of $0.3^{\circ}$ has been observed.

It is questionable to base a cross-talk estimation on one of the algorithms using distributed targets, because these targets in the spring tend to have a fairly low backscatter coefficient at L-band and hence a very low signal-to-interference ratio. However, it can be shown [10] that by using the trihedrals it is possible to estimate the sum of the transmit and receive $H$ to $V$ cross-talk terms as well as the sum of the transmit and receive $\mathrm{V}$ to $\mathrm{H}$ cross-talk terms. At $\mathrm{L}$ band, the radar cross section of the present trihedrals are really not large enough to justify this procedure, but it will anyway give an upper limit. The above-mentioned sums are found to be below some $-20 \mathrm{~dB}$. In case the cross-talk terms add up in-phase, the cross-talk is found to be better than -26 $\mathrm{dB}$. By design the cross-talk is known to be below $-35 \mathrm{~dB}$ and this method is clealy too crude for the present radar.

\section{References}

[1] Madsen, S.N., Christensen, E.L., Skou, N., and Dall, J., "The Danish SAR System; Design and Initial Tests", IEEE Transactions on Geoscience and Remote Sensing, Vol 29, No 3, May 1991, pp 417-426.

[2] Dall, J., Jørgensen, J.H., Christensen, E.L., and Madsen, S.N., "Real-Time Processor for the Danish Airborne SAR", IEE Proceedings Part F, Special part on Remote Sensing, pp 115-121, April 1992.

[3] Dall, J., Jørgensen, J.H., Netterstrøm, A., Vardi, N., Christensen, E.L., and Madsen, S.N., "The Danish Real Time SAR Processor: First Results", IGARSS '93, 1993 International Geoscience and Remote Sensing Symposium, Tokyo, August 18-21, 1993, Vol. 3, pp 1401-1403.

[4] Christensen, E.L., Madsen, S.N., Dall, J., Skou, N., Jørgensen, J.H., Woelders, K., Netterstrøm, A., Granholm, J., Dich, M., "The Danish Polarimetric SAR for Remote Sensing Applications", IGARSS '94, 1994
International Geoscience and Remote Sensing Symposium, California, USA, 8-12 August 1994, Vol. 3, pp 1361-1364.

[5] Skou, N., "The Danish Polarimetric SAR System", Second International Workshop on Radar Polarimetry, Nantes, France, 8-10. September 1992, pp 525-533.

[6] Dall, J., Skou, N., and Christensen, E.L., "Pulse based Internal Calibration of Polarimetric SAR", IGARSS '94, 1994 International Geoscience and Remote Sensing Symposium, California, USA, 8-12 August 1994, Vol. 4, pp 2205-2208.

[7] Woelders, K. and Granholm, J., "Design and Performance of a Dual-Linearly Polarized C-band Microstrip Array Antenna", Second International Workshop on Radar Polarimetry, Nantes, France, Sept. 1992, pp. 369 378.

[8] Granholm, J., Woelders, K., Dich, M., and Christensen, E.L.. "Microstrip Antenna for Polarimetric C-band SAR", IEEE AP-S International Symposium and URSI Radio Science Meeting, Seattle, Washington, June 1924, 1994, pp. 1844-1847.

[9] Christensen, E.L., and Dich, M., "SAR Antenna Design for Ambiguity and Multipath Suppression", IGARSS '93, 1993 International Geoscience and Remote Sensing Symposium, Tokyo, August 18-21, 1993, Vol. 2, pp. 784-787.

[10] Dall J., "Polarimetric Calibration with Corner Reflectors", R 575, Electromagnetics Institute, Technical University of Denmark, February, 1994, 14 pp. 